to local authorities. Today I am in exactly the same position. I have one year left and my staff will have to follow me into the street since the school will not support them beyond the termination of my own grant." Simmonds intends to devote her political energies in the coming year to collecting data on the current treatment of senior scientists like herself. As far as her research goes she is more philosphical. "Although it is difficult to believe that there is no official recognition when one has done something as clinically useful as describing a new disease, we have to accept that we are in the wrong field with the wrong qualifications."

\section{Where MRC stands on jobs}

THE Medical Research Council's current career structure for non-clinical scientific staff was agreed with the Association of University Teachers and came into force in 1974. It applies only to staff in the MRC's units and provides for three categories of appointment: three-year short term contracts, five year limited term appointments and tenured posts.

In general a new $\mathrm{PhD}$ would apply first for a three-year short term contract. At the age of about 27, after completing one three year term, he/she would then eligible to apply for a five year limited term appointment. At the end of that, at age about 31 , he/she can apply for tenure.

The five year limited term appointment was created as a bridge between postdoctoral appointments supported by short term grants and tenured posts. The idea was that $75 \%$ of those with limited term appointments would receive tenure at the end of five years. Those who did not, would not normally be eligible for further three or five year appointments. This scheme was designed to prevent researchers continuing work on limited term grants into middle age by forcing them into a career decision in their early thirties.

The MRC currently employes 790 nonclinical scientific staff in its units. $21 \%$ of them are on short term contracts, $14 \%$ on limited term and $65 \%$ have unlimited tenure. The target figures, which the Council would hope to achieve after the system had been working for several years, are $18 \%, 15 \%$ and $67 \%$ respectively. However, with pressure on budgets due to public expenditure cuts, the MRC may never achieve these figures. It has recently been rethinking the career structure for non-clinical scientific staff and has put forward a proposal to the AUT for negotiation, which is likely to include a major modification of the tenure system.

The position in the universities is very different. The MRC provides tenured staff with grants for research projects. Untenured staff are paid out of these grants, the university being their employer. The MRC currently provides funds for $800-900$ research studentships and 1300-1400 scientists on short term contracts. Half of the latter have PhDs and half have only first degrees.

Seven years ago, the MRC began to realise the problem of absorbing all these short term contract workers into permanent positions. It has, however, according to one official been surprised at how slow the crisis has been in coming. Many people have left the system by taking jobs overseas or moving right out of research. "The problem (of short term contract workers) will solve itself by the scientists making an appreciation themselves and then making the necessary adjustments". However, the Council does not know how far the process of adaptation has gone and criticises the AUT's attempts to quantify the problems. “'The (AUT's) figure of 2500 unemployed scientists hasn't been substantiated and we don't really know if there is a problem, whether people have been able to adapt and whether able people have been discouraged from entering research",

The MRC's main response to the lack of tenured posts has been to create bridging fellowships to enable the "truly able" postdoctoral worker to wait longer than the normal five year limited term for the right tenured position to turn up. But the scheme has met with minimal response. The Council has also resisted pressure from within its own ranks and outside to recruit more graduate students.

Ideally, the MRC would like to have more control over research posts. Two MRC officials at least would like to judge the "hallowedness and timeliness" of research and to see a "population of mobile research workers who could move around at the Council's discretion"'. Another, Tony Vickers, told a meeting at the Royal Society of Medicine earlier this year that "it might not be a bad idea if we had to revert to immediate post-war conditions". This would mean a much smaller scale of scientific activity with no post-doctoral researchers. "Serendipity goes out of the window when postdoctoral workers come in".

The Association of Scientific, Technical and Managerial Staffs has been trying for several years to gain $50 \%$ membership on the MRC. Its attempts, however, have been resisted. It just wants "to turn Council into a private benefit society" according to one MRC official. "The Council is a selfperpetuating oligarchy" which has trust in its members who in turn have trust in it.

ASTMS, however, takes a different view. It considers fixed term contracts as a "primitive way of dealing with scientific and technical staff"' which places "too much power in the hands of incompetent employers at a time of particular difficulties in scientific employment".

Judy Redfearn

\section{SRC: university cuts are the greatest threat}

"The science vote is not being harshly treated" by the Conservative government in the latest round of public expenditure cuts, according to Sir Geoffrey Allen, Chairman of the UK Science Research Council. There is a good case for maintaining a reasonable budget for research, he says, and this is having a strong influence on the government. The science budget is therefore unlikely to suffer the massive percentage cuts proposed for other areas of public expenditure such as education and many of the social services.

The SRC budget is to be cut by only $1 \frac{1}{2} \%$ in real terms in the current financial year and a further $2 \%$ in $1980-81$. The lack of budget guidelines after 1981, however, is causing problems with medium term planning. For example, the Council's recently announced programmes in post graduate education to improve the performance of graduates in industry (Nature 2 August, page 347) are to receive priority over the next few years - but uncertainty in future budgets means that the rate of expansion of the programmes cannot be planned in advance.

Similarly, the SRC cannot plan space and astronomy beyond the end of the current programme in 1983. International collaboration may be one way of cutting costs, says Sir Geoffrey.

The greatest threat to the level of science funding in the UK, however, probably comes from the recently announced cuts in the universities budgets. "These are bound to affect science and engineering"', says Sir Geoffrey especially in the short term when running costs will be squeezed. In the long term science and engineering will be cut proportionately less than other faculties and will therefore make a greater part of a smaller whole. "This could be good from our point of view. The government is saying that we've got to be more selective. This means either fewer universities or a smaller overall staff maintaining quality".

Sir Geoffrey hopes that the problem of providing employment for scientists (and coping with any redundancies the universities may have to make) will be helped by the SRC's research felowship scheme whereby senior scientists can vacate tenured posts by taking up SRC fellowship. "We have the money to do this on a small scale".

Sir Geoffrey's belief in the government's empathy for research was endorsed by the Prime Minister, Mrs Margaret Thatcher, herself last week when she told members of the Chemical Society of her committment to basic research at a ceremony to award her with the Society's Honorary Fellowship. "One must listen to the voices of scientists and pay attention to what they say", she said. 